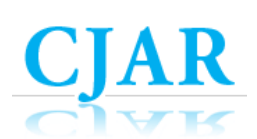

Canadian Journal of Action Research

Volume 20, Issue 2, 2020, pages 1-2

\title{
ACTION RESEARCHERS TO THE RESCUE An Editorial
}

\author{
Marianne Barker \\ Managing Editor
}

"We live in interesting times" might be the most common understatement of 2020 so far. A global pandemic and subsequent social distancing measures have generated countless changes, and sometimes complete blocks, in everybody's routines. Educators, teachers and learners are certainly in the middle of this. Schools of all levels across Canada have closed indefinitely, extra-curricular activities and events have been cancelled, teaching and learning have moved online, research projects have been put on pause, and stakeholders will be wrestling with the logistical and affective aspects of these changes for the foreseeable future.

As educators chart a path forward during these times, Action Research constitutes a wonderfully dynamic approach to research. Action Research can extend into the far corners of diverse contexts to explore and improve practices. The methodology offers a flexibility in responding to research problems that, frankly, other research methodologies cannot. As things change more quickly than ever, and indeed as our familiar model of education has been turned upside down in recent months, Action Research is at the forefront in responding. With one foot in practice and one foot in research, action researchers step forward towards improving their immediate localities.

In this issue, several articles demonstrate how action research benefits communities in diverse educational spaces. Sara Santarossa and Sarah Woodruff describe a community-academic partnership dedicated to educating mothers as they navigate social networking sites. Their action research project uniquely works with parents to encourage adaptation in an always-changing digital age. The toolkit and workshop resulting from their action research project suggests exciting potential to widely impact motherdaughter relationships, digital identities, and related affective aspects. Edward Howe and Andres Ruberg explore how a DigiPen, an innovative secondary school course, develops learners' programing skills through project-based learning. The authors outline how DigiPen positively impacted student perceptions of computer science through an integrated skills course, while simultaneously fostering leadership skills, a sense of teamwork and inclusion. 
Ruby Hanson's article focuses on using worksheets with pre-service teachers to allow them to integrate their understanding of chemical equations. Hanson's findings suggest that reflective learning can reinforce a link between theory and practice, which is the heart of action research. Sharon Bratt's article aims to critically evaluate the design of courses that use community-engaged learning as a pedagogical approach. Bratt outlines the tenets of community-engaged learning, and recommends strategies to deliver communityengaged learning courses that are reflective, knowledge enhancing and civically engaged. Bratt's work reminds us how it important it is to develop courses that serve a public purpose and meet real life needs.

In a reflective theoretical article, John Freeman thoughtfully considers how best to approach the intersection of community-based projects and action research goals. Freeman uses autoethnography to explore what it means to be a responsible researcher. He raises questions about protecting participant identities, researcher positionality, and the overall appropriateness of action research in community-based research and dissemination. Freeman's questions about the validity and value of action research highlight reflection as a tool to sharpen our understanding of Action Research and ensure that its primary interest is benefiting the immediate locality or community.

The articles in this issue exhibit how Action research can respond to and effect change by uniting theory and practice. Action Research pushes toward better practices and better communities. In our current times of unprecedented change and challenging circumstances, how will action researchers respond? Could Action Research play a role in moving forward learning and teaching in diverse educational spaces? Of course, I fully recognize that our communities' front line medical staff and public health workers are the real heroes of our days - and remain grateful for their bravery, expertise and dedication. But, in the realm of education, I believe it is time for innovative teacher researchers to move us forward. With one foot firmly in the community and one foot in research - action researchers to the rescue. 